\title{
Mediation effects of clinical practice stress between clinical education environment and satisfaction with clinical practice
}

\author{
Youngsoon Park', Kyunghee Chun $^{1}$ and Mihye Kwon ${ }^{2}$ \\ Departments of ${ }^{1}$ Medical Education and ${ }^{2}$ Internal Medicine, Konyang University College of Medicine, Daejeon, \\ Korea
}

Purpose: The purpose of this study was to identify the possible correlations of 'satisfaction with clinical practice (SA)' with 'clinical learning environment (EN)' and 'clinical practice stress (ST).' We searched for the mediating effect of 'clinical practice stress' on 'satisfaction with clinical practice' when the clinical learning environment influences 'satisfaction with clinical practice.'

Methods: This research investigated 208 medical and nursing students attending the school of medicine and nursing in Korea. The total number of nursing students was 135 (64.9\%); 73 medical students participated (35.1\%). We used the Korean-Undergraduate Clinical Education Environment in 24 questions for EN, ST scale in 24 questions, and SA scale in 10 questions. We performed measurement structural equation model analysis to identify a path of the model.

Results: Medical students had significantly higher levels of ST. EN had a significant negative correlation with ST and a significant positive correlation with SA. The ST had a significant negative correlation with SA. The results of the goodness of fit index have fulfilled the criteria of goodness of fit. There was a significant mediating effect of ST on SA when EN influences SA.

Conclusion: The clinical learning environment affected satisfaction with the clinical practice directly or indirectly mediated by clinical practice stress. Therefore, educational institutes should try to increase satisfaction with clinical practice by continuously monitoring and improving the clinical learning environment in addition to taking measures for decreasing the clinical practice stress.

Key Words: Clinical learning environment, Student satisfaction, Stress, Mediation effect

\section{Introduction}

In general, the teacher, student, curriculum, and educational environment are considered significant education components. In clinical practice, students and supervisors, clinical practice programs, and clinical learning environments are the main factors for successful learning. For nursing students with a high level of satisfaction with clinical clerkship, autonomous and responsible learning occurred more [1,2]. However, when students had excessive stress and negative experiences, they had significant emotional hardship, including maladaptation, anxiety, and nervousness [3]. Particularly, those who experience high-stress levels during their clinical education tended to have lower satisfaction, performance, and nursing professionalism [4]. Medical students' satisfaction with clinical practice has affected professional attitudes, career commitment, and retention [5,6]. Clinical practice was stressful
Received: January 18, 2021 • Revised: February 5, 2021 • Accepted: February 8, 2021 Corresponding Author: Kyunghee Chun (https://orcid.org/0000-0002-5351-0376) Department of Medical Education, Konyang University College of Medicine, 158 Gwanjeodong-ro, Seo-gu, Daejeon 35365, Korea

Tel: +82.42.600.8654 Fax: +82.0504.042.6603 email: khchun@konyang.ac.kr
Korean J Med Educ 2021 Mar; 33(1): 27-36 https://doi.org/10.3946/kjme.2021.184 eISSN: 2005-7288

(C) The Korean Society of Medical Education. All rights reserved. This is an open-access article distributed under the terms of the Creative Commons Attribution Non-Commercial License (http:// creativecommons.org/licenses/by-nc/3.0/), which permits unrestricted non-commercial use, distribution, and reproduction in any medium, provided the original work is properly cited. 
because of having to deal with patients and unpredictable schedules in a new environment. The main stressors of trainees were context, communication, clinical scenario, and learning tasks [7].

The clinical learning environment affects learning, learners' well-being, and satisfaction [8,9], thereby affecting learning ability, learning attitude, and career development [10]. Considering the significance of clinical practice in nursing and medical education, monitoring and improving the clinical learning environment is of great importance. Besides the regular curriculum, the hidden curriculum also has a considerable influence on learners. Therefore, hidden curriculum and environments should be considered one of the essential educational processes, and it is necessary to measure the educational environment and improve it. Thus, researchers have developed measurement tools for the clinical learning environment to analyze the educational environment [11-14].

However, the measurement tools had limitations in measuring some critical educational phenomena since many of them lack a theoretical basis, consider the clinical learning environment as a mere educational arena, and fail to acknowledge that it is a workplace as well [9,15]. They mainly measured either learning conditions in clinical placement or learning environments and supervision $[13,14]$. When measuring learning conditions, they assessed learning modeling, coaching, elaboration, research, and safety; and, when assessing learning environments and supervision, they measured the relationship with preceptors, educational environments, leadership style, and patient-related matters. To assess the clinical learning environments, learning opportunities, student participation, quality of supervision, workplace interaction pattern, and equal treatment extent also need to be factored in. The $\mathrm{re}^{-}$ presentative scale measuring those factors is the
Undergraduate Clinical Education Environment Measure (UCEEM), which was developed to measure how undergraduate medical students perceive the educational climate in clinical environments and measure factors related to their learning and social interaction [16]. This scale has been verified in nursing and medical school's practice environment and can be used in both areas [17,18].

The factors that influenced one's satisfaction with the clinical practice were practice workload, stress, emotional intelligence, and communication skills. The inter-professional relationships with fellow students, faculties, patients, and co-workers affected professional self-concept formation $[16,19]$. The primary factors that affect learners' satisfaction with the clinical practice were the clinical learning environments as an external factor and clerkship stress as an internal factor. The stress of clerkship had negative correlations with students' burnout, and satisfaction with a clerkship and resilience had a buffering effect on physical needs without mediating the psychological needs [20]. The stresses associated with clinical clerkship were inappropriate role modeling, a burden from practice workload, interpersonal conflicts, and conflicts with patients [21]. Students' stress did not merely influence satisfaction with clerkship, but it also had adverse psychical and psychological effects on them. Therefore, medical and nursing schools need to consider stress management and provide more support to students during their clerkship [22].

The purpose of this study was to identify the level of 'satisfaction with clinical practice' in nursing and medical students who were doing their clinical practice in the one teaching hospital. Through this, we tried to find out the educational climate. We examined the possible correlations between 'satisfaction with clinical practice $(\mathrm{SA})$ ' and 'clinical learning environments, (EN)' and 
'clinical practice stress, (ST),' respectively. Furthermore, we examined whether ST has a mediating effect on SA when the EN influences SA. Through this study, we would like to discuss what efforts are required by nursing and medical schools to improve learners' satisfaction during clinical practice.

\section{Methods}

\section{Participants}

Two hundred and twenty-nine medical and nursing students attending the school of medicine and nursing, Konyang University, Daejeon, South Korea responded to the questionnaire, of which 208 were included in this study. The total number of nursing students was 135 (64.9\%), of which the number of third-year students was 100 (48.1\%), and fourth-year students were 35 (16.8\%). The number of female students was 124 (91.85\%), and male students were 11 (8.15\%). Seventy-three medical students participated (35.1\%), of which 29 (13.9\%) were third-year students, 44 (21.2\%) were a fourth-year students; with 24 (32.88\%) female students and 49 (67.12\%) male students. Nursing students had at least 3 to 8 weeks of clinical practice experience in a teaching hospital and should participate in orientation, ward round, core fundamental nursing skill learning, and case conference. Nursing professionals with a master's degree or higher were in charge of clinical practice, and full-time faculty of a nursing college must direct at least $30 \%$ of the training course. Medical students had at least 24 to 56 weeks of clinical practice experience in a teaching hospital and must practice at least 36 hours per week. Faculties of medical college and residents as teachers were in charge of clinical practice. The subjects were nursing and medical students who participated in clinical practice in 2018-2019, and they agreed to participate after receiving information about the research contents before the survey. The Institutional Review Board of Tongmyung University approved this study (ethics consent no., TUIRB-2020-009).

\section{Measurement tools}

\section{1) K-UCEEM}

To measure the clinical learning environment (EN), we used Korean-UCEEM developed by Strand et al. [16] modified by Chun et al. [23] to adapt to the Korean context. This scale measures the educational climate and social interactions perceived by students. This scale consists of 24 questions based on five factors: workplace interaction pattern, equal treatment, quality of learning and supervision, clinical learning environment readiness, and learning opportunity. The examples of questions include "I feel included in the team of people who work here," "Everyone is treated equally here regardless of gender," and "I have adequate access to computers in this placement." Each question was scored on a 5-point Likert scale, and a higher score indicated higher levels of positive perceptions of the EN. The Cronbach's $\alpha$ was 0.939, and the sub-factors of the scale were from 0.769 to 0.880 .

\section{2) Clinical practice stress}

To measure the clinical practice stress (ST), we used the scale developed by Beck and Sriavastava [21] modified by Kim and Lee [24]. This scale measures the level of stress perceived by students in clinical practice. It consists of 24 questions based on five factors: clinical learning environment, inappropriate role modeling, practice workload, interpersonal conflicts, and conflicts with patients. The examples of questions are "Space and facility for the clinical clerkship are lacking," "The preceptors are not friendly and are indifferent towards the students," and "The practice workload is too 
burdensome." Each question was rated on a 5-point Likert scale, and a higher score indicated a higher ST level. The Cronbach's $\alpha$ was 0.890 , and the sub-factors of the scale were from 0.743 to 0.854 .

\section{3) Satisfaction with clinical practice}

To measure the satisfaction with clinical practice (SA), we used four questions of Maastricht Clinical Teaching Questionnaire developed by Stalmeijer et al. [12] related to satisfaction with coaching and general satisfaction and five questions from the Manchester Clinical Placement Index developed by Dornan et al. [13] related to satisfaction with the clinical learning environment. The examples of questions are "Offered me sufficient opportunities to perform activities independently" and "This placement provided appropriate facilities." Each question was scored on a 5-point Likert scale, and a higher score indicated higher levels of SA. The scales were translated and validated in Korean according to standard procedures before being used for nursing and medical students. The Cronbach's $\alpha$ was 0.878 , and the sub-factors of the scale were from 0.838 to 0.844 .

\section{Analysis}

Data were analyzed using IBM SPSS ver. 21.0 (IBM Corp., Armonk, USA), AMOS ver. 22.0 (IBM Corp.), and frequency analysis to evaluate participants' demographics. We calculated Cronbach's $\alpha$ for reliability evaluation. Additionally, the relationships between variables were determined by using Pearson's correlation coefficient analysis. We examined whether the observable variables in this study were appropriate for explaining the latent variables using structural equation modeling (SEM), then we performed "measurement model" analysis and "structural equation model" analysis to identify the path of the model. We used the bootstrapping method to analyze the mediation effect, sufficient for indirect effect analysis [25]. To evaluate the goodness of fit of the research model, we used $\chi^{2}$ (CMIN), root mean square residual (RMR), goodness of fit index (GFI), and root mean square error of approximation (RMSEA) for the absolute fit index, Tucker-Lewis index (TLI) and comparative fit index (CFI) for the incremental fit index.

\section{Results}

\section{Differences in EN, ST, and SA between nursing and medical students}

Table 1 shows the results of examining EN, ST, and SA perceived by students. In the sub-factors of EN, medical students perceived "workplace interaction" $(\mathrm{t}=7.427, \mathrm{p}<0.01)$, "Equal treatment" $(\mathrm{t}=10.448, \mathrm{p}<0.01)$, and "preparedness for students" $(\mathrm{t}=15.689, \mathrm{p}<0.001)$ higher than nursing students. In the sub-factors of ST, nursing students perceived "uncomfortable clinical environment" ( $\mathrm{t}=26.159, \mathrm{p}<0.001)$, "undesirable role models" ( $\mathrm{t}=58.337, \mathrm{p}<0.001)$, and "assignments and workload" $(\mathrm{t}=30.170, \mathrm{p}<0.001)$ higher than medical students. In the sub-factors of SA, medical students perceived "satisfaction with educational environments" $(t=5.255, p<0.001)$, "satisfaction with coaching" $(t=3.369$, $\mathrm{p}<0.01)$, and "general satisfaction" $(\mathrm{t}=4.808, \mathrm{p}<0.001)$ higher than nursing students.

\section{Relationship between the variables}

Results of correlation analysis between EN, ST, and SA were as follows. First, EN had a significant negative correlation with ST $(r=0.322, p<0.01)$ and a significant positive correlation with $\mathrm{SA}(\mathrm{r}=0.807, \mathrm{p}<0.01)$. The ST had a significant negative correlation with $\mathrm{SA}(\mathrm{r}=0.270$, $\mathrm{p}<0.01$ ). The results of correlation analysis among sub-factors of EN, ST, and SA are shown in Table 2. 
Table 1. Differences in EN, ST, and SA between Nursing and Medical Students

\begin{tabular}{|c|c|c|c|c|}
\hline Variable & Nursing student $(n=135)$ & Medical student $(n=73)$ & Total $(n=208)$ & t-value \\
\hline \multicolumn{5}{|l|}{ EN } \\
\hline Workplace interaction & $3.29 \pm 0.72$ & $3.59 \pm 0.86$ & $3.39 \pm 0.79$ & $7.427^{* *}$ \\
\hline Equal treatment & $3.16 \pm 0.94$ & $3.59 \pm 0.83$ & $3.31 \pm 0.93$ & $10.448^{* *}$ \\
\hline Quality of learning \& supervision & $3.71 \pm 0.55$ & $3.72 \pm 0.65$ & $3.71 \pm 0.59$ & 0.025 \\
\hline Preparedness for students & $2.96 \pm 0.78$ & $3.40 \pm 0.76$ & $3.12 \pm 0.80$ & $15.689 * * *$ \\
\hline Opportunities to learning & $3.66 \pm 0.59$ & $3.65 \pm 0.73$ & $3.66 \pm 0.64$ & 0.024 \\
\hline \multicolumn{5}{|l|}{ ST } \\
\hline Clinical environment & $3.67 \pm 0.60$ & $3.17 \pm 0.80$ & $3.50 \pm 0.71$ & $26.159 * * *$ \\
\hline Undesirable role models & $3.35 \pm 0.67$ & $2.56 \pm 0.78$ & $3.07 \pm 0.80$ & $58.337^{* * *}$ \\
\hline Assignments and workload & $3.68 \pm 0.61$ & $3.15 \pm 0.76$ & $3.50 \pm 0.71$ & $30.170^{* * *}$ \\
\hline Interpersonal relationships & $2.71 \pm 0.83$ & $2.83 \pm 0.72$ & $2.75 \pm 0.80$ & 1.199 \\
\hline Conflict with patients & $2.54 \pm 0.80$ & $2.69 \pm 0.81$ & $2.59 \pm 0.80$ & 1.734 \\
\hline \multicolumn{5}{|l|}{ SA } \\
\hline Satisfaction with the learning environment & $3.71 \pm 0.83$ & $4.37 \pm 0.91$ & $3.94 \pm 0.91$ & $27.617^{* * *}$ \\
\hline Coaching satisfaction & $3.34 \pm 0.79$ & $3.71 \pm 0.68$ & $3.47 \pm 0.77$ & $11.351^{* *}$ \\
\hline Overall satisfaction & $6.38 \pm 1.79$ & $7.56 \pm 1.50$ & $6.79 \pm 1.78$ & $23.119 * * *$ \\
\hline
\end{tabular}

Data are presented as mean \pm standard deviation.

EN: Clinical learning environment, ST: Clinical practice stress, SA: Satisfaction with clinical practice.

${ }^{* *} p<0.01 .{ }^{* * *} p<0.001$.

\begin{tabular}{|c|c|c|c|c|c|c|c|c|c|c|c|c|c|}
\hline & EN1 & EN2 & EN3 & EN4 & EN5 & ST1 & ST2 & ST3 & ST4 & ST5 & SA1 & SA2 & SA3 \\
\hline EN1 & - & & & & & & & & & & & & \\
\hline EN2 & $0.564^{* *}$ & - & & & & & & & & & & & \\
\hline EN3 & $0.648^{* *}$ & $0.444^{* *}$ & - & & & & & & & & & & \\
\hline EN4 & $0.665^{* *}$ & $0.500^{* *}$ & $0.578^{* *}$ & - & & & & & & & & & \\
\hline EN5 & $0.703^{* *}$ & $0.431^{* *}$ & $0.767^{* *}$ & $0.562^{* *}$ & - & & & & & & & & \\
\hline ST1 & $-0.270^{* *}$ & $-0.268^{* *}$ & -0.133 & $-0.417^{* *}$ & $-0.153^{*}$ & - & & & & & & & \\
\hline ST2 & $-0.320^{* *}$ & $-0.294^{* *}$ & $-0.202^{* *}$ & $-0.336^{* *}$ & $-0.243^{* *}$ & $0.493^{* *}$ & - & & & & & & \\
\hline ST3 & $-0.200^{* *}$ & $-0.214^{* *}$ & -0.065 & $-0.315^{* *}$ & -0.097 & $0.511^{* *}$ & $0.586^{* *}$ & - & & & & & \\
\hline ST4 & -0.136 & $-0.140^{*}$ & $-0.196^{* *}$ & -0.099 & $-0.237^{* *}$ & $0.172^{*}$ & $0.343^{* *}$ & $0.301^{* *}$ & - & & & & \\
\hline ST5 & -0.056 & 0.079 & $-0.165^{*}$ & 0.040 & $-0.180^{* *}$ & 0.083 & $0.297^{* *}$ & 0.121 & $0.575^{* *}$ & - & & & \\
\hline SA1 & $0.650^{* *}$ & $0.513^{* *}$ & $0.638^{* *}$ & $0.632^{* *}$ & $0.628^{* *}$ & $-0.234^{* *}$ & $-0.394^{* *}$ & $-0.244^{* *}$ & -0.133 & -0.010 & - & & \\
\hline SA2 & $0.585^{* *}$ & $0.389 * *$ & $0.561^{* *}$ & $0.586^{* *}$ & $0.617^{* *}$ & $-0.190^{* *}$ & $-0.266^{* *}$ & $-0.226^{* *}$ & $-0.199 * *$ & -0.093 & $0.581^{* *}$ & - & \\
\hline SA3 & $0.582^{* *}$ & $0.403^{* *}$ & $0.587^{* *}$ & $0.578^{* *}$ & $0.556^{* *}$ & $-0.283^{* *}$ & $-0.333^{* *}$ & $-0.205^{* *}$ & $-0.206^{* *}$ & -0.101 & $0.581^{* *}$ & $0.595^{* *}$ & - \\
\hline
\end{tabular}

EN1: Workplace interaction, EN2: Equal treatment, EN3: Quality of learning \& supervision, EN4: Preparedness for students, EN5: Learning opportunities, ST1: Clinical environment, ST2: Undesirable role models, ST3: Assignments and workload, ST4: Interpersonal relationships, ST5: Conflict with patients, SA1: Satisfaction with the learning environment, SA2: Coaching satisfaction, SA3: Overall satisfaction.

${ }^{*} \mathrm{p}<0.5 .{ }^{* *} \mathrm{p}<0.01$. ${ }^{* * *} \mathrm{p}<0.001$.

\section{Mediation effect of ST on the EN and the SA}

For the SEM analysis, we performed exploratory factor analysis to ensure that the observable variables used to measure the EN, ST, and SA could explain the latent variables. For parameter estimation, we used the maximum likelihood method. The results of goodness of fit index were as follows: $\chi^{2}=133.841(\mathrm{p}<0.001$, degrees of freedom $[\mathrm{df}]=59), \chi^{2} / \mathrm{df}=2.268$, RMR $=0.037$, GFI= 0.909, TLI $=0.927, \mathrm{CFI}=0.945$, and RMSEA $=0.078$. The $\chi^{2}$ value was sensitive to sample size, that other GFI were 
considered together, then GFI, TLI, CFI were more than 0.90 [26,27], and RMSEA was less than 0.08 [28], fulfilled the criteria of goodness of fit. Since the factor loading $(\beta)$ was from 0.30 to $0.83(\mathrm{p}<0.01)$ and met the criteria of more than absolute value for factor loading of 0.30, it was considered that the observable variables could appropriately explain each latent variable (Table 3). We analyzed the SEM to determine the path with which EN affects ST on SA.

The goodness of fit index results were CMIN/ $\mathrm{DF}=2.297(\mathrm{p}<0.001), \mathrm{RMR}=0.039, \mathrm{GFI}=0.914$, TLI=0.925, CFI=0.946, and RMSEA=0.079, which showed ap-

Table 3. Factor Loading of the Measurement Model

\begin{tabular}{|c|c|c|c|c|}
\hline Variable & $B$ & $\beta$ & SE & CR \\
\hline \multicolumn{5}{|l|}{ EN } \\
\hline Learning opportunities & 1.00 & 0.76 & & \\
\hline Preparedness for students & 1.28 & 0.79 & 0.111 & $11.588^{* * *}$ \\
\hline Quality of learning \& supervision & 0.92 & 0.77 & 0.061 & $14.934^{* * *}$ \\
\hline Equal treatment & 1.16 & 0.67 & 0.132 & $8.802^{* * *}$ \\
\hline Workplace interaction & 1.34 & 0.83 & 0.098 & $13.596 * *$ \\
\hline \multicolumn{5}{|l|}{ ST } \\
\hline Conflict with patients & 1.00 & 0.30 & & \\
\hline Interpersonal relationships & 1.54 & 0.40 & 0.385 & $3.994^{* * *}$ \\
\hline Assignments and workload & 2.54 & 0.73 & 0.777 & $3.268^{* *}$ \\
\hline Undesirable role models & 3.18 & 0.81 & 0.966 & $3.286^{* *}$ \\
\hline Clinical environment & 2.20 & 0.63 & 0.685 & $3.210^{* *}$ \\
\hline \multicolumn{5}{|l|}{ SA } \\
\hline Overall satisfaction & 1.00 & 0.74 & & \\
\hline Coaching satisfaction & 0.43 & 0.73 & 0.041 & $10.458 * * *$ \\
\hline Satisfaction with the learning environment & 0.56 & 0.81 & 0.049 & $11.544^{* * *}$ \\
\hline
\end{tabular}

SE: Standard error, CR: Critical ratio, EN: Clinical learning environment, ST: Clinical practice stress, SA: Satisfaction with clinical practice. ${ }^{* *} p<0.01 .{ }^{* *} p<0.001$.

Fig. 1. The Path Coefficients of the Final Model

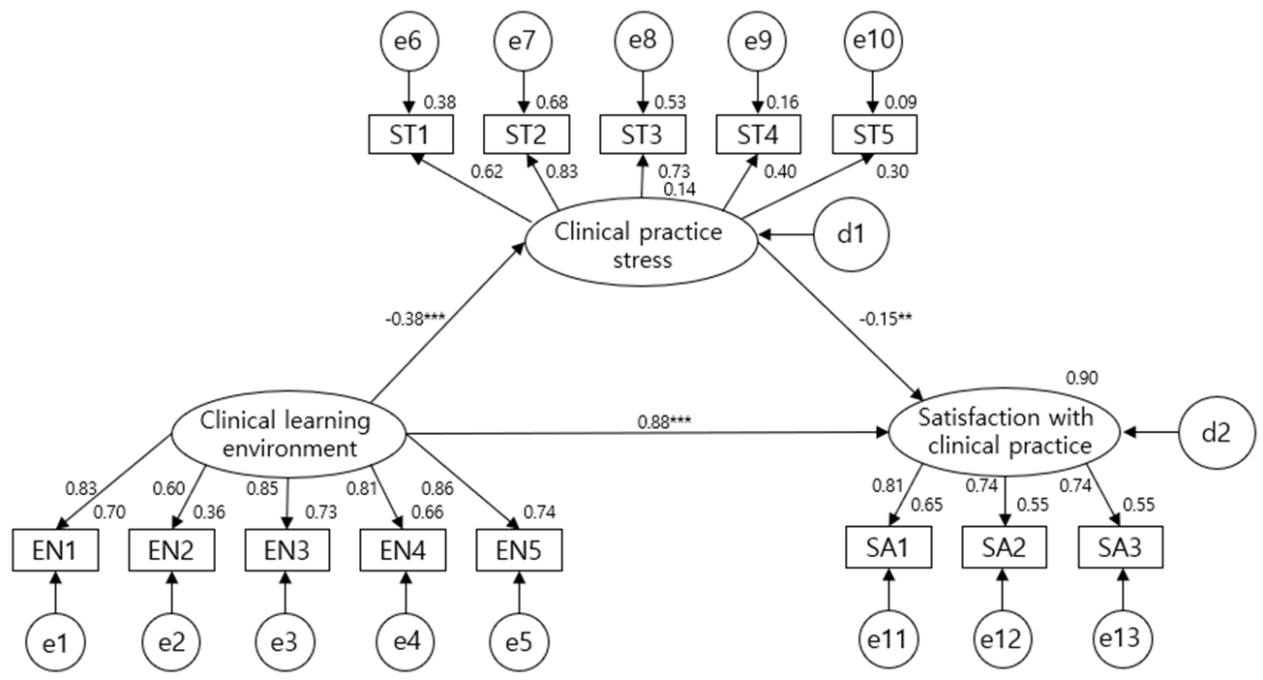

EN1: Workplace interaction, EN2: Equal treatment, EN3: Quality of learning \& supervision, EN4: Preparedness for students, EN5: Learning opportunities, ST1: Clinical environment, ST2: Undesirable role models, ST3: Assignments and workload, ST4: Interpersonal relationships, ST5: Conflict with patients, SA1: Satisfaction with the learning environment, SA2: Coaching satisfaction, SA3: Overall satisfaction. ${ }^{* *} p<0.01 .{ }^{* * *} p<0.001$. 
Table 4. Direct, Indirect, and Total Effects of Model

\begin{tabular}{cccc}
\hline Path & Total effect & Direct effect & Indirect effect \\
\hline $\mathrm{EN} \rightarrow \mathrm{T}$ & $-0.379^{* * *}$ & $-0.379^{* * *}$ & 0.000 \\
$\mathrm{ST} \rightarrow \mathrm{A}$ & $-0.151^{* *}$ & $-0.151^{* *}$ & 0.000 \\
$\mathrm{EN} \rightarrow \mathrm{A}$ & $0.937^{* *}$ & $0.880^{* * *}$ & $0.057^{*}$ \\
\hline
\end{tabular}

EN: Clinical learning environment, ST: Clinical practice stress, SA: Satisfaction with clinical practice.

${ }^{*} \mathrm{p}<0.5 .{ }^{* *} \mathrm{p}<0.01 .{ }^{* * *} \mathrm{p}<0.001$.

propriate goodness of fit (Fig. 1). The results identified as significant from path analysis are shown in Table 4. EN had a positive impact on SA $(\beta=0.880, p<0.001)$. Otherwise, EN negatively affected SA $(\beta=-0.151$, $\mathrm{p}<0.01)$ through ST $(\beta=-0.379, p<0.001)$. Lastly, we performed bias-corrected bootstrapping to verify the significance of the indirect effect of the EN through ST on SA (Table 4), and the indirect effect was 0.057 $(\mathrm{p}<0.05)$.

\section{Discussion}

This study examined EN, ST, and SA perceived by nursing and medical students and investigated EN and ST's effects on SA. Also, the mediating effect of ST in EN affecting SA was verified.

Despite having practiced in the same hospital, nursing students had significantly lower SA than medical students and experienced more clinical practice stress. Such differences can be attributed to contents and methods of training and the leadership style of educators, and the type of coaching [29]. It may also be due to the difference in gender ratio in that the ratio of female students to nursing students is higher than that of medical students. These results are consistent with several series of studies suggesting that female students had a higher level of stress and fatigue and a lower level of satisfaction during clinical clerkship [30-34]. Due to the differences in the results, it is necessary to investigate if the differences in satisfaction levels between the two groups resulted from the differences in factors such as practice methods, jobs, education-related culture, and gender role differences. Although the practice was conducted in the one teaching hospital, the contents of clinical practice, duration of the training, and teaching style of training staff could differ in the nursing and medical college. Therefore, it is necessary to deal in-depth in subsequent studies on the differences in perceptions of students' environment, stress, and satisfaction, and their causes.

EN was positively correlated with SA from correlation analysis between EN, ST, and SA. And there were negative correlations between EN and ST, and ST and SA. These results were consistent with that of previous studies $[2,4,6,7]$. In other words, students with more perception of stress had lower satisfaction. This study aimed to identify ST's mediation effect on where the EN affected SA beyond a simple relationship between the variables. As a result, the mediation effect of ST was significant. The EN directly affected SA, and it had an indirect effect on SA. When students perceived the EN positively, they were less stressed and perceived higher SA. Therefore, educational institutes need to regularly inspect the clinical learning environment and monitor how cultural, physical, and human factors are perceived.

Additionally, they need to provide counseling and systematic support services to help the students reduce their stress and deal with interpersonal conflicts or conflicts with patients. Most of all, the learning 
environment factors identified in this study, such as workplace interaction, equal treatment, quality of learning and supervision, preparedness for students, and learning opportunities, should be improved. Moreover, the stress from inappropriate role modeling and practice workload should be reduced by means of the curriculum improvement and the faculty development programs. The consistent efforts to reduce the students' stress include decreasing the discrepancies between students' expectations and the real educational environments and solving the inconsistencies between the pre-clerkship education and the clinical practice [22].

In conclusion, with the current study on the differences in SA between nursing and medical students, and the relationship between EN and ST affecting the SA, we identified environmental improvement and stress reduction for improving students' satisfaction with their clinical practice. The EN affected SA directly or indirectly mediated by ST. Because the current study was performed on clinical practice in a single teaching hospital, validation of multicenter follow-up study results is necessary. Furthermore, we suggest some research subjects identifying the reasons for the difference in satisfaction with clinical practice according to gender and the effects of consistent monitoring and measures for environmental education improvement on learners. We hope this study be useful in improving the quality of clinical clerkship.

\section{ORCID:}

Youngsoon Park: https://orcid.org/0000-0002-3644-8793; Kyunghee Chun: https://orcid.org/0000-0002-5351-0376; Mihye Kwon: https://orcid.org/0000-0002-1660-1770

Acknowledgements: None.

Funding: None.

Conflicts of interest: No potential conflict of interest relevant to this article was reported.

Author contributions: KHC: conception or design of the work and critical revision of the article; YSP: data analysis and drafting the article; MHK: first revision of the article; and all authors: final approval of the version to be published.

\section{References}

1. Yang NY, Moon SY. Relationship of self-leadership, stress and satisfaction in clinical practice of nursing students. J Korean Acad Nurs Adm. 2011;17(2): 216-225.

2. Jung JS. Relationship of self-directedness and practice satisfaction to clinical practice in nursing students: the mediating effect of clinical competence. J Korean Acad Soc Nurs Educ. 2012;18(1):53-61.

3. Lee SH, Kim SY, Kim JA. Nursing students' image of nurse and satisfaction with clinical practice. J Korean Acad Nurs Adm. 2004;10(2):219-231.

4. Elliott M. Clinical environment: a source of stress for undergraduate nurses. Aust J Adv Nurs. 2002;20(1): 34-38.

5. Shelley RK, Webb MG. Does clinical clerkship alter students' attitudes to a career choice of psychiatry? Med Educ. 1986;20(4):330-334.

6. Ziaee V, Ahmadinejad Z, Morravedji AR. An evaluation on medical students' satisfaction with clinical education and its effective factors. Med Educ Online. 2004;9(1): 4365.

7. Johnson NR, Pelletier A, Chen X, Manning-Geist BL. Learning in a high-stress clinical environment: stressors associated with medical students' clerkship training on labor and delivery. Teach Learn Med. 2019;31(4): 385-392.

8. Genn JM. AMEE medical education guide no. 23 (part 
2): curriculum, environment, climate, quality and change in medical education: a unifying perspective. Med Teach. $2001 ; 23(5): 445-454$.

9. Roberts R, Cleland J, Strand P, Johnston P. Medical students' views of clinical environments. Clin Teach. 2018;15(4):325-330.

10. Hoff TJ, Pohl H, Bartfield J. Creating a learning environment to produce competent residents: the roles of culture and context. Acad Med. 2004;79(6):532-539.

11. Roff SU, McAleer S, Harden RM, et al. Development and validation of the Dundee ready education environment measure (DREEM). Med Teach. 1997; 19(4):295-299.

12. Stalmeijer RE, Dolmans DH, Wolfhagen IH, Muijtjens AM, Scherpbier AJ. The Maastricht Clinical Teaching Questionnaire (MCTQ) as a valid and reliable instrument for the evaluation of clinical teachers. Acad Med. 2010;85(11):1732-1738.

13. Dornan T, Muijtjens A, Graham J, Scherpbier A, Boshuizen H. Manchester Clinical Placement Index (MCPI): conditions for medical students' learning in hospital and community placements. Adv Health Sci Educ Theory Pract. 2012;17(5):703-716.

14. Öhman E, Alinaghizadeh H, Kaila P, Hult H, Nilsson GH, Salminen H. Adaptation and validation of the instrument Clinical Learning Environment and Supervision for medical students in primary health care. BMC Med Educ. 2016;16(1):308.

15. Daelmans HE, Hoogenboom RJ, Donker AJ, Scherpbier AJ, Stehouwer CD, van der Vleuten CP. Effectiveness of clinical rotations as a learning environment for achieving competences. Med Teach. 2004;26(4):305-312.

16. Strand P, Sjöborg K, Stalmeijer R, Wichmann-Hansen G, Jakobsson U, Edgren G. Development and psychometric evaluation of the Undergraduate Clinical Education Environment Measure (UCEEM). Med Teach. 2013; 35(12):1014-1026.
17. Abbasi Z, Ahmadi S, Esmaeilpour ZS. Psychometric properties of Undergraduate Clinical Education Environment Measure (UCEEM) in nursing and midwifery students in Iran. J Urmia Nurs Midwifery Fac. 2016; 14(2):145-150.

18. Fouad S, El Araby S, Abed RA, Hefny M, Fouad M. Using item response theory (IRT) to assess psychometric properties of Undergraduate Clinical Education Environment Measure (UCEEM) among medical students at the Faculty of Medicine, Suez Canal University. Educ Med J. 2020;12(1):15-27.

19. Yu JH, Lee SK, Kim M, Chae SJ, Lim KY, Chang KH. Medical students' satisfaction with clinical clerkship and its relationship with professional self-concept. Korean J Med Educ. 2019;31(2):125-133.

20. Lin YK, Lin CD, Lin BY, Chen DY. Medical students' resilience: a protective role on stress and quality of life in clerkship. BMC Med Educ. 2019;19(1):473.

21. Beck DL, Srivastava R. Perceived level and sources of stress in baccalaureate nursing students. J Nurs Educ. 1991;30(3):127-133.

22. Benbassat J, Baumal R, Chan S, Nirel N. Sources of distress during medical training and clinical practice: suggestions for reducing their impact. Med Teach. 2011 ;33(6):486-490.

23. Chun K, Park YS, Oak JW. Validation of the Korean version of the Undergraduate Clinical Education Environment Measure. Korean Med Educ Rev. 2021;23(1): $37-45$.

24. Kim SL, Lee JE. Relationship among stress, coping strategies, and self-esteem in nursing students taking clinical experience. J Korean Acad Soc Nurs Educ. 2005;11(1):98-106.

25. Bollen KA, Stine RA. Bootstrapping goodness-of-fit measures in structural equation models. Sociol Methods Res. 1992;21(2):205-229.

26. Bentler PM. Comparative fit indexes in structural 
Youngsoon Park, et al: Mediation effects of clinical practice stress between environment and satisfaction

models. Psychol Bull. 1990;107(2):238-246.

27. Tucker LR, Lewis C. A reliability coefficient for maximum likelihood factor analysis. Psychometrika. $1973 ; 38(1): 1-10$.

28. Browne MW, Cudeck R. Alternative ways of assessing model fit. In: Bollen KA, Long JS, eds. Testing Structural Equation Model. Newbury Park, USA: Sage; 1993: 136-162.

29. D’Souza MS, Karkada SN, Parahoo K, Venkatesaperumal R. Perception of and satisfaction with the clinical learning environment among nursing students. Nurse Educ Today. 2015;35(6):833-840.

30. Vyas KS, Stratton TD, Soares NS. Sources of medical student stress. Educ Health (Abingdon). 2017;30(3):
232-235.

31. Kwon MS. The influence of self-directed learning \& critical thinking disposition on clinical competence in nursing students. J Korean Acad Soc Nurs Educ. 201 1; 17(3):387-394.

32. Lee AK, You HS, Park IH. Affecting factors on stress of clinical practice in nursing students. J Korean Acad Nurs Adm. 2015;21(2):154-163.

33. Yang YK, Han KS, Bae MH, Yang SH. Social support, academic stress, clinical practice stress in college student of nursing. Korean J Stress Res. 2014;22(1):23-34.

34. Hyoung HK, Ju YS, Im SI. A concept mapping study on clinical stress for nursing students during clinical practice. J Korean Acad Nurs Adm. 2014;20(4):394-404. 